\title{
The effects of lidocaine spray and intracuff alkalinized lidocaine on the occurrence of cough at extubation: a double-blind randomized controlled trial
}

\section{Effets de la lidocaïne vaporisée et de la lidocaïne alcalinisée dans le ballonnet sur la survenue de toux au moment de l'extubation: une étude randomisée contrôlée à double insu}

\author{
Frédérick D'Aragon, MD • Nicolas Beaudet, $\mathrm{PhD}(\mathrm{c}) \cdot$ \\ Véronique Gagnon, RRT • René Martin, MD • \\ Yanick Sansoucy, MD \\ Received: 6 February 2012/Accepted: 13 December 2012/Published online: 1 February 2013 \\ (C) Canadian Anesthesiologists' Society 2013
}

\begin{abstract}
Purpose Our study aimed to evaluate the effects of lidocaine sprayed onto the larynx and/or injected into the tracheal tube cuff to decrease the incidence of cough at extubation and postoperative sore throat.

Methods One hundred twenty women scheduled for gynecological surgery $<120 \mathrm{~min}$ in duration were enrolled in this randomized double-blind prospective study. Prior to tracheal intubation, $4 \%$ lidocaine or $0.9 \%$ saline was sprayed onto the patients' supra-and subglottic areas.

This report was presented in part at the 2011 Association des anesthésiologistes du Québec Congress and the 2011 Canadian Anesthesiologists' Society Annual Meeting.

Author contributions René Martin and Yanick Sansoucy designed the study. Véronique Gagnon and Yanick Sansoucy conducted the study. Frédérick D'Aragon, Nicolas Beaudet, and Yanick Sansoucy analyzed the data and reviewed the analysis of the data. Frédérick D'Aragon, Nicolas Beaudet, René Martin, and Yanick Sansoucy wrote the manuscript. Véronique Gagnon is the author responsible for archiving the study files. Frédérick D'Aragon, Nicolas Beaudet, René Martin, Véronique Gagnon, and Yanick Sansoucy have seen the original study data.
\end{abstract}

F. D'Aragon, MD · V. Gagnon, RRT · R. Martin, MD ·

Y. Sansoucy, MD ( $\square)$

Department of Anesthesiology, Faculty of Medicine and Health

Sciences, Université de Sherbrooke, 3001, 12e Avenue Nord,

Sherbrooke, QC J1H 5N4, Canada

e-mail: yanick.sansoucy@usherbrooke.ca

N. Beaudet, $\mathrm{PhD}(\mathrm{c})$

Department of Physiology and Biophysics, Faculty of

Medicine and Health Sciences, Université de

Sherbrooke, Sherbrooke, QC, Canada
After tracheal intubation, the tracheal tube cuff was filled with either an alkalinized $2 \%$ lidocaine solution or $0.9 \%$ saline. This resulted in four groups: spray-cuff, spray-saline, saline-cuff, and saline-saline. A logistic regression comprising the two factors was used for analysis. The primary outcome was the incidence of cough at extubation. The secondary outcome was the incidence and severity of sore throat reported by patients at $15 \mathrm{~min}$, $60 \mathrm{~min}$, and $24 \mathrm{hr}$ after tracheal extubation.

Results Cough occurred in 42\%, 24\%, 63\%, and 69\% of patients in the spray-cuff, spray-saline, saline-cuff, and saline-saline groups, respectively. The use of lidocaine spray decreased the incidence of cough at extubation (odds ratio $=0.256 ; 95 \%$ confidence interval 0.118 to 0.554 ; $P<0.001)$; however, the use of intracuff alkalinized lidocaine had no impact on the occurrence of cough $(P=0.471)$. Severity of sore throat was clinically low (visual analog scale $[V A S] \leq 3)$ in all groups. No significant difference was observed in hoarseness, dysphagia, nausea, or vomiting.

Conclusion Sprayed lidocaine decreases the incidence of cough at tracheal extubation in surgeries of less than two hours. The use of alkalinized lidocaine into high-volumel low-pressure endotracheal cuffs had no impact on decreasing the incidence of cough or pain.

Résumé

Objectif Notre étude avait pour objectif d'évaluer les effets de la lidocaïne vaporisée sur le larynx et/ou injectée dans le ballonnet de la sonde trachéale pour réduire l'incidence de toux au moment de l'extubation et de maux de gorge postopératoires. 
Méthode Cent-vingt femmes devant subir une chirurgie gynécologique d'une durée $<120 \mathrm{~min}$ ont été recrutées pour cette étude prospective randomisée à double insu. Avant l'intubation trachéale, on a vaporisé de la lidocaïne $4 \%$ ou du chlorure de sodium 0,9\% sur les zones supra- et sous-glottiques des patientes. Après l'intubation trachéale, le ballonnet de la sonde trachéale a été rempli avec une solution de lidocä̈ne alcalinisée $2 \%$ ou du $\mathrm{NaCl}$ 0,9\%. Nous avons ainsi créé quatre groupes: vaporisationballonnet, vaporisation - $\mathrm{NaCl}, \mathrm{NaCl}$ - ballonnet, et $\mathrm{NaCl}-\mathrm{NaCl}$. Une régression logistique incluant les deux facteurs a été utilisée pour l'analyse. Le critère d'évaluation primaire était l'incidence de toux lors de l'extubation. Le critère d'évaluation secondaire était l'incidence et la gravité des maux de gorge rapportés par les patientes à $15 \mathrm{~min}, 60 \mathrm{~min}$ et $24 \mathrm{~h}$ après l'extubation trachéale.

Résultats La toux est survenue chez 42\%, $24 \%, 63 \%$ et $69 \%$ des patientes dans les groupes vaporisation-ballonnet, vaporisation - $\mathrm{NaCl}, \mathrm{NaCl}$ - ballonnet, et $\mathrm{NaCl}-\mathrm{NaCl}$, respectivement. L'utilisation de lidocä̈e en vaporisation a réduit l'incidence de toux lors de l'extubation (rapport de cotes $=0,256$; intervalle de confiance $95 \% 0,118$ à 0,554; $P<0,001)$; toutefois, l'utilisation de lidocaine alcalinisée dans le ballonnet n'a pas eu d'impact sur la survenue de toux $(P=0,471)$. La gravité des maux de gorge était faible d'un point de vue clinique (échelle visuelle analogique $[E V A] \leq 3$ ) dans tous les groupes. Aucune différence significative n'a été observée en termes d'enrouement, de dysphagie, de nausées ou de vomissements.

Conclusion La lidocaïne vaporisée réduit l'incidence de toux lors de l'extubation trachéale après une chirurgie de moins de deux heures. L'utilisation de lidocaine alcalinisée dans les ballonnets endotrachéaux à haut volume / faible pression n'a eu aucun impact pour réduire l'incidence de toux ou de douleur.

Tracheal intubation provokes a transitory irritation of the laryngopharyngeal mucosa, resulting in undesirable effects at emergence, and sore throat, dysphagia, and/or dysphonia are reported in approximately $50 \%$ of cases. ${ }^{1-4}$ Cough can be more problematic, leading to hemodynamic alterations, arrhythmias, increase in intraocular and intracranial pressures, bronchospasm, and postoperative surgical complications. ${ }^{5}$ According to the literature, the incidence of cough at emergence ranges from 40 to $96 \%$. $^{6-10}$

Different methods have been proposed to decrease the adverse effects associated with mucosal irritation caused by the endotracheal tube (ETT), including the administration of opioids, extubation under deep anesthesia, use of fluticasone, and injection of intravenous lidocaine., ${ }^{40-15}$ Although intravenous anesthetics have been shown to be effective in reducing the incidence of cough at emergence, time can be delayed until the patient can respond to simple orders. ${ }^{16}$ Thus, topical local anesthetics represent an attractive alternative to suppress cough while maintaining rapid awakening. Administration of $2-4 \%$ lidocaine to the glottic area before the end of surgery was associated with a $32-69 \%$ decrease in the incidence of cough. ${ }^{16,17}$ Minogue et al. administered $4 \%$ lidocaine with a syringe fitted with a multi-orifice cannula before intubation, and this resulted in a significant decrease in the incidence of peri-extubation cough. ${ }^{6}$ Other researchers have opted to lubricate the ETT cuff to decrease mucosal irritation. ${ }^{8,9,18,19}$ For surgical procedures exceeding two hours, intracuff alkalinized $2 \%$ lidocaine has been shown to be more effective in decreasing the incidence of cough than a cuff filled with air or lidocaine alone. This effect was due primarily to the semi-permeable properties of the high-pressure/low-volume ETT cuff membrane and the high $\mathrm{pH}$ of the solution allowing gradual diffusion of lidocaine. ${ }^{7,8}$ Nevertheless, none of these methods, when used alone, suppressed cough entirely at extubation.

Therefore, the goal of this study was to evaluate the impact of lidocaine sprayed locally on the supra- and subglottic areas $v s$ the effect of using ETT intracuff alkalinized lidocaine. We wanted to evaluate both approaches, used alone and in combination, on known undesirable effects at tracheal extubation, i.e., cough and sore throat, following surgical procedures under general anesthesia lasting less than two hours.

\section{Methods}

\section{Participants}

One hundred twenty adult female patients were enrolled in this double-blind randomized controlled trial from April 2006 to July 2010. Participants were American Society of Anesthesiologists (ASA) physical status I or II who were scheduled for elective gynecologic procedures of approximately 30-120 min. Surgeries took place at the Centre Hospitalier Universitaire de Sherbrooke (CHUS), a tertiary care hospital centre. The local Institutional Ethics Committee of the CHUS (comité d'éthique de la recherche sur l'humain du CHUS) approved the protocol for the first time on November 28, 2005, and the protocol was approved annually up to October 2010. All participants provided written informed consent before enrolment.

Exclusion criteria included symptomatic gastric reflux despite medication; history of, or anticipated, difficult airway; a nasogastric tube in place; an upper respiratory tract infection in the last month; pulmonary disease; and lidocaine hypersensitivity. 


\section{Material}

The ETTs used in this study had an internal diameter of 7 mm (Mallinckrodt Inc., St. Louis, MO, USA; model \# 86111) and featured a long thin-walled large-volume lowpressure barrel-shaped cuff made of a polyvinylchloride membrane. The topical lidocaine was sprayed using a sterile disposable LTA $360 \mathrm{Kit}^{\circledR}$ (Hospira Healthcare Corporation, Montreal, QC, Canada) designed to deliver its content in a circumferential pattern over the supra- and subglottic areas. The device is made of an anatomicallycurved plastic cannula with an attached single-use vial injector prefilled with $4 \mathrm{~mL}$ of a $4 \%$ sterile aqueous lidocaine hydrochloride solution.

\section{Protocol}

Four treatment groups were planned based on 120 patients randomized in 30 blocks of four patients each using a permuted block design with a computer random number generator. All patients received a standardized anesthetic consisting of $100 \%$ preoxygenation, fentanyl $2-3 \mu \mathrm{g} \cdot \mathrm{kg}^{-1}$ $i v$, propofol $2-3 \mathrm{mg} \cdot \mathrm{kg}^{-1} i v$, and rocuronium $0.6 \mathrm{mg} \cdot \mathrm{kg}^{-1}$ $i v$. Before tracheal intubation, $4 \%$ lidocaine hydrochloride $4 \mathrm{~mL}$ or the equivalent volume of $0.9 \%$ saline was sprayed using an LTA $360 \mathrm{Kits}^{\circledR}$. After intubation, the ETT cuff was prefilled with $2 \%$ lidocaine $2 \mathrm{~mL}$ or an equivalent volume of saline and fluid was added in the ETT cuff to obtain a seal at a positive airway pressure of $30 \mathrm{cmH}_{2} \mathrm{O}$; this fluid was $8.4 \%(\mathrm{v} / \mathrm{v})$ sodium bicarbonate in patients who had received lidocaine in the cuff or saline in patients who already received saline. Thus, the patients were allocated to four groups: Group spray-cuff received both lidocaine spray and lidocaine in the cuff; Group spraysaline was treated with a lidocaine spray and saline in the tube cuff; Group saline-cuff received a saline spray and alkalinized lidocaine in the tube cuff; and Group salinesaline received saline both as a spray and in the cuff.

All cuff solutions and modified LTA $360 \mathrm{Kits}^{\circledR}{ }^{\circledR}$ (lidocaine substituted by saline) were prepared by a nonparticipating anesthesiologist or resident physician. No difference could be detected between kits. Under general anesthesia, after complete neuromuscular relaxation as monitored with a peripheral nerve stimulator, the LTA 360 $\mathrm{Kit}^{\circledR}$ was introduced between the patients' vocal cords under direct vision to deliver the experimental solution (lidocaine or saline). Laryngoscopy was performed with a Macintosh blade either by a senior resident or a certified anesthesiologist. The ETT cuff was filled with the experimental solution (lidocaine or saline) immediately after ETT insertion and cuff volume was adjusted to maintain a seal at an airway pressure of $30 \mathrm{cmH}_{2} \mathrm{O}$. Anesthesia was maintained with desflurane in an oxygen/air mixture (1:1).
Anesthesiologists were allowed to provide fentanyl $1 \mu \mathrm{g} \cdot \mathrm{kg}^{-1}$ and/or rocuronium $0.15 \mathrm{mg} \cdot \mathrm{kg}^{-1}$ if required during surgery. No other local anesthetic was allowed during the procedure by either the anesthesiologists or the surgeons, otherwise the participant would be excluded from the study. If the cuff pressure decreased during surgery, additional saline or bicarbonate could be injected into the cuff.

At the end of the surgery, every patient received ondansetron $4 \mathrm{mg} i \mathrm{v}$. Residual neuromuscular blockade was reversed with neostigmine and glycopyrrolate, and pharyngeal secretions were gently aspirated before the desflurane vaporizer was turned off. Tracheal extubation was performed when the patients were responsive to simple orders.

\section{Outcomes monitoring}

Cough at tracheal extubation was the primary outcome of this study and was determined during the time interval from the moment desflurane was turned off until appropriate spontaneous and unassisted ventilation was present after extubation. In this period of time, the patient remained on the operating room table without any stimulation. The same investigator, blinded to group assignment, systematically assessed the presence or absence of cough with a "yes" or a "no" evaluation. For the secondary outcomes, patients reported severity of sore throat and dysphagia using a visual analogue scale (VAS 0-10) at $15 \mathrm{~min}$, one hour, and $24 \mathrm{hr}$ after extubation, either at the bedside or by phone when the patient was sent home. Postoperative nausea and vomiting (PONV) and agitation were also recorded. The following variables were noted in addition to socio-demographic data: ASA status, duration of surgery, history of tobacco use, occurrence of bronchospasm or laryngospasm, fentanyl use during surgery and $30 \mathrm{~min}$ before extubation.

Statistical analyses

The sample size was determined according to a previous study. ${ }^{6}$ We estimated a $70 \%$ incidence of cough at extubation and aimed for a $50 \%$ decrease (i.e., $35 \%$ incidence of cough). Hence, a sample size of 120 patients ( 30 per group) was calculated to provide $80 \%$ power for a 0.05 level of significance. Incidence of cough among the four groups was analyzed using the Chi square test or the Fisher's exact test if expected frequencies were $<5$. A multivariate logistic regression analysis was conducted to determine the specific impact of $4 \%$ lidocaine spray and intracuff alkalinized 2\% lidocaine as risks factors for resulting cough. Odds ratios (OR) with a $95 \%$ confidence interval (CI) are reported. The number needed-to-treat 
(NNT) was calculated to determine the effectiveness of the significant experimental treatments on the incidence of cough at extubation. Pain scores (low, VAS $\leq 3 / 10$; moderate, VAS 4-6; and high, $\geq 7 / 10$ ), incidence of smoking, administration of opioids $30 \mathrm{~min}$ before the end of surgery, and other secondary outcomes (e.g., the need for additional saline or bicarbonate in the cuff), PONV, dysphagia, and agitation were analyzed using Chi square and Fisher's exact tests. The Kruskal-Wallis test was used for the volume of liquid used in the ETT cuffs. Categorical data are expressed as frequency and percentage, and normally distributed continuous data are reported as the mean with standard deviation, otherwise as median with quartiles. All analyses and plotting were performed with IBM SPSS $^{\circledR} 18.0$ (Armonk, NY, USA) and GraphPad 5.00 (San Diego, CA, USA).

\section{Results}

Four of the 120 participants were excluded because of protocol violations. Two patients were excluded in Group spray-cuff; one patient had a nasogastric tube inserted and succinylcholine was used in another patient for tracheal intubation. One patient in Group spray-saline had a nasogastric tube inserted, and in Group saline-saline, one patient was excluded because sevoflurane was used instead of desflurane. Baseline demographic and clinical characteristics were similar in all groups (Table 1).

Cuffs were prefilled initially with $2 \mathrm{~mL}$ of either $2 \%$ lidocaine or $0.9 \%$ saline. To reach a final seal of $30 \mathrm{cmH}_{2} \mathrm{O}$, the cuffs were then filled with $8.4 \%$ bicarbonate or saline as follows: a mean volume of $3.7 \mathrm{~mL}, 3.6 \mathrm{~mL}, 3.9 \mathrm{~mL}$, and $3.7 \mathrm{~mL}$ for Groups spray-cuff, spray-saline, saline-cuff, and saline-saline, respectively $(P=0.526)$. The resulting mean final cuff volumes were $5.7 \mathrm{~mL}, 5.6 \mathrm{~mL}, 5.9 \mathrm{~mL}$, and $5.7 \mathrm{~mL}$, respectively. To compensate for leaks during the surgery, an additional $18 \%, 7 \%, 13 \%$, and $10 \%$ of the initial volume was injected in the four groups, respectively
$(P=0.628)$. Cough at extubation differed between the four groups $(P=0.002)$ (Table 2$)$. Logistic regression analysis showed a strong association between the use of sprayed lidocaine and a decrease in the incidence of cough at extubation $(P<0.001)$ (Table 3), with patients being 3.91 times less likely to cough $(\mathrm{OR}=0.256 ; 95 \% \mathrm{CI} 0.118$ to 0.554$)$. In contrast, intracuff alkalinized lidocaine had no impact on the incidence of peri-extubation cough $(\mathrm{OR}=1.329 ; 95 \% \mathrm{CI}$ 0.614 to $2.877 ; P=0.471)$. For sprayed lidocaine, the NNT was 3.05 .

Severity of sore throat remained low (VAS $\leq 3$ ) for $>80 \%$ of the patients irrespective of the post-extubation monitoring time and experimental group (Table 4). There was no statistically significant difference between groups with respect to PONV or dysphagia, and no bronchospasm was observed.

\section{Discussion}

This study shows that lidocaine sprayed onto the glottis area decreases the incidence of cough at extubation in surgeries of less than two hours. Alkalinized lidocaine injected into highvolume/low-pressure ETT cuffs had no impact on the incidence of post-extubation cough or sore throat.

Peri-extubation cough leads to undesirable postoperative events, especially in patients at risk for complications related to increases in intracranial or intraocular pressure. Cough can be triggered by mechanical or chemical stimuli that activate sensory receptors distributed along the respiratory tract. ${ }^{20}$ Some agents inhibit all neural reflexes in a non-selective manner. ${ }^{21}$

In one study reporting the use of the LTA $360 \mathrm{Kit}^{\circledR}$ and its effects on the incidence of cough at extubation, laryngotracheal topicalization with lidocaine prior to intubation decreased the incidence of cough on emergence from general anesthesia. ${ }^{6}$ Our findings confirm the results of that study but for surgical procedures of two hours or less. Our results also show that intracuff alkalinized lidocaine alone

Table 1 Baseline demographic and clinical characteristics

\begin{tabular}{lllll}
\hline & $\begin{array}{l}\text { Group spray-cuff } \\
(n=28)\end{array}$ & $\begin{array}{l}\text { Group spray-saline } \\
(n=29)\end{array}$ & $\begin{array}{l}\text { Group saline-cuff } \\
(n=30)\end{array}$ & $\begin{array}{l}\text { Group saline-saline } \\
(n=29)\end{array}$ \\
\hline Age $(\mathrm{yr})$, mean (SD) & $43.8(9.9)$ & $46.0(10.5)$ & $43.0(9.1)$ & $40.6(9.5)$ \\
Weight $(\mathrm{kg})$, mean (SD) & $72.9(15.7)$ & $67.8(12.8)$ & $68.2(11.1)$ & $67.6(13.4)$ \\
Height $(\mathrm{cm})$, mean (SD) & $162.2(5.9)$ & $159.8(4.3)$ & $160.5(5.8)$ & $162.1(6.1)$ \\
Smoking $(\%)$ & $21 \%$ & $28 \%$ & $43 \%$ & $28 \%$ \\
Duration of anesthesia (min), mean (SD) & $81.7(29.4)$ & $96.7(21.4)$ & $87.0(31.6)$ & $91.2(39.8)$ \\
Fentanyl $(\mu \mathrm{g})$, median $[\mathrm{IQR}]$ & $223[150-250]$ & $217[188-250]$ & $241[200-250]$ & $225[170-250]$ \\
Fentanyl $<30$ min before extubation $(\%)$ & $14 \%$ & $31 \%$ & $30 \%$ & $21 \%$ \\
\hline
\end{tabular}

$\mathrm{IQR}=$ interquartile range; $\mathrm{SD}=$ standard deviation 
Table 2 Peri-extubation cough

\begin{tabular}{llll}
\hline $\begin{array}{l}\text { Group Spray - Cuff } \\
(n=28)\end{array}$ & $\begin{array}{l}\text { Group Spray -Saline } \\
(n=29)\end{array}$ & $\begin{array}{l}\text { Group Saline - Cuff } \\
(n=30)\end{array}$ & $\begin{array}{l}\text { Group Saline - Saline } \\
(n=29)\end{array}$ \\
\hline $12(42 \%)$ & $7(24 \%)$ & $19(63 \%)$ & $20(69 \%)$ \\
\hline
\end{tabular}

Data are expressed as $n(\%) . P=0.002$

Table 3 Multivariate logistic regression for risk of cough

\begin{tabular}{llr}
\hline & Odds ratio $(95 \% \mathrm{CI})$ & $P$ value \\
\hline Sprayed lidocaine* & $0.256(0.118$ to 0.554$)$ & $<0.001$ \\
Intracuff alkalinized lidocaine & $1.329(0.614$ to 2.877$)$ & 0.471 \\
\hline
\end{tabular}

$\mathrm{CI}=$ confidence interval. $*$ Number needed-to-treat: 3.05

had no effect on decreasing the incidence of cough and did not potentiate the effect of sprayed lidocaine on preventing the occurrence of cough. This is in contrast to the results of a study by Estebe et al. in which they reported fewer occurrences of pre-extubation cough by using intracuff alkalinized lidocaine in surgeries of approximately 60 min. $^{9}$ In their study, anesthesiologists or surgeons performed thyroidectomies in which they could apply, without restriction, local anesthetics or vasoconstrictor agents to the larynx. The use of these agents could have contributed to reducing the cough reflex through an additive effect on the anesthetics used in the intubation protocol. In our study, we controlled this confounding variable by using a strict perisurgical standardized anesthetic protocol for both surgical and anesthesiology teams and by choosing a surgical site distant from the airway structures. Moreover, our analyses were based on the occurrence of either pre- or post-extubation cough, while the aforementioned study reported the efficacy of alkalinized lidocaine on decreasing the occurrence of cough in the post-extubation period. Also, the cuffs in their control group were filled with air instead of liquid. There is evidence that air-filled cuffs induce more episodes of cough than cuffs filled with normal saline. ${ }^{22}$ For that reason and to facilitate the blinding procedure, the cuffs of all our patients were filled with a liquid (saline or lidocaine). In addition, we hypothesize that the contact area between the tracheal mucosa and the highvolume/low-pressure cuff is smaller than that between the tracheal mucosa and a low-volume/high-pressure cuff, as used in other studies, thus contributing to the difference in our data $v s$ previous studies. ${ }^{23}$

We can also speculate that the duration of surgery in our case was too short to allow for substantial lidocaine diffusion through the ETT cuff, therefore resulting in the absence of clear physiological benefit on the pharyngolaryngeal mucosa using this approach. Indeed, Estebe et al. have shown that it took three hours for $25 \%$ of alkalinized lidocaine $(8.4 \%$ sodium bicarbonate) to diffuse through the semi-permeable membrane of a low-volume/high-pressure ETT cuff. ${ }^{9}$ When estimating the diffusion rate based on their data, likely only $10 \%$ of the alkalinized lidocaine in the cuff

Table 4 Secondary outcomes

Data are expressed as $n(\%)$. $\mathrm{PONV}=$ postoperative nausea and vomiting

\begin{tabular}{|c|c|c|c|c|c|}
\hline & $\begin{array}{l}\text { Group } \\
\text { spray-cuff } \\
(n=28)\end{array}$ & $\begin{array}{l}\text { Group } \\
\text { spray-saline } \\
(n=29)\end{array}$ & $\begin{array}{l}\text { Group } \\
\text { saline-cuff } \\
(n=30)\end{array}$ & $\begin{array}{l}\text { Group } \\
\text { saline-saline } \\
(n=29)\end{array}$ & $P$ value \\
\hline PONV & $7(25 \%)$ & $9(31 \%)$ & $6(20 \%)$ & $4(14 \%)$ & 0.443 \\
\hline Agitation & $3(11 \%)$ & $3(10 \%)$ & $6(20 \%)$ & $8(28 \%)$ & 0.247 \\
\hline Dysphagia & $9(32 \%)$ & $5(17 \%)$ & $6(20 \%)$ & $3(10 \%)$ & 0.218 \\
\hline Sore throat severity & & & & & 0.859 \\
\hline \multicolumn{6}{|l|}{$15 \min$} \\
\hline Low $\leq 3 / 10$ & $25(89.3)$ & $26(89.7)$ & $27(90)$ & $24(82.8)$ & \\
\hline Moderate 4-6/10 & $3(10.7)$ & $3(10.3)$ & $3(10)$ & $5(17.2)$ & \\
\hline High $\geq 7 / 10$ & $0(0)$ & $0(0)$ & $0(0)$ & $0(0)$ & \\
\hline $60 \mathrm{~min}$ & & & & & 0.375 \\
\hline Low $\leq 3 / 10$ & $27(96.4)$ & $28(96.6)$ & $27(90)$ & $29(100)$ & \\
\hline Moderate $4-6 / 10$ & $1(3.6)$ & $1(3.4)$ & $3(10)$ & $0(0)$ & \\
\hline High $\geq 7 / 10$ & $0(0)$ & $0(0)$ & $0(0)$ & $0(0)$ & \\
\hline $24 \mathrm{hr}$ & & & & & 0.857 \\
\hline Low $\leq 3 / 10$ & $26(92.9)$ & $28(96.6)$ & $28(93.3)$ & $28(96.6)$ & \\
\hline Moderate 4-6/10 & $2(7.1)$ & $1(3.4)$ & $2(6.7)$ & $1(3.4)$ & \\
\hline High $\geq 7 / 10$ & $0(0)$ & $0(0)$ & $0(0)$ & $0(0)$ & \\
\hline
\end{tabular}


would have diffused through the membrane at $90 \mathrm{~min}$ (a time corresponding to the mean duration of our gynecologic surgeries). The in vitro diffusion rate of alkalinized lidocaine was found to be similar to low-volume/high-pressure cuffs and high-volume/low-pressure cuffs. ${ }^{8}$

Other groups have proposed to prefill the ETT cuffs with lidocaine $90 \mathrm{~min}$ prior to intubation in order to condition the cuff's semi-permeable membrane. ${ }^{18,19}$ This approach could yield interesting results in the case of short duration surgeries, but it remains time-consuming in a day-to-day clinical setting. Other avenues to increase the diffusion rate of lidocaine through the cuff membrane throughout $60 \mathrm{~min}$ could involve increasing the lidocaine concentrations to $4 \%$ while decreasing the bicarbonate concentrations, since there is only a slight difference between release rates using $1.4 \%$ and $8.4 \%$ sodium bicarbonate. $^{9}$ The development of new semi-permeable cuff membranes (polyurethane) could also be promising for increasing the diffusion rate of liquids between the cuff and the pharyngolaryngeal mucosa.

Ours is a novel study to evaluate the severity of pharyngolaryngeal pain when using a LTA $360 \mathrm{Kit}^{\circledR}$ for surgeries of short duration. In the study by Minogue et al., the authors evaluated the efficacy of the LTA $360 \mathrm{Kit}^{\circledR}$ with respect to the occurrence of cough but not sore throat. ${ }^{6}$ Dehydration and irritation of the mucosa are responsible for mucosal pain following intubation; ${ }^{19}$ thus, it is important to monitor pain even after surgery of short duration. In contrast with other studies where $10 \%$ lidocaine, sterile water, or water soluble gels were used as lubricants, ${ }^{7-9,18,19}$ in our study, the outside wall of the cuff membrane was not lubricated prior to its use. The VAS scores monitored in our study were in the low range $(\leq 3 / 10)$, similar to those reported by Estebe et $_{\text {al. }}{ }^{7,8}$ or by Navarro et al. ${ }^{19}$ at one hour and $24 \mathrm{hr}$. In our study, there was no potentiating effect on pain when sprayed lidocaine was combined with intracuff alkalinized lidocaine; however our results indicate that filling the ETT cuff with a volume of either saline or alkalinized lidocaine contributes to maintaining a low level of pain after the extubation. This supports a previous observation by Navarro et al. that showed intracuff alkalinized lidocaine to result in less irritation on the throat than air-filled cuffs at $24 \mathrm{hr}$ postextubation. ${ }^{24}$ In our study, we used only $2 \mathrm{~mL}$ of $2 \%$ intracuff alkalinized lidocaine. In the future, increasing the volume to $4 \mathrm{~mL}$ and increasing the concentration to $4 \%$ need to be tested to determine whether this could result in a better diffusion rate. Finally, we opted for gynecological procedures for our study to avoid confounding effects due to the proximity of the intervention site with laryngeal structures. In a future design, we could aim for long duration neurosurgical procedures to determine the efficacy of the approach on the incidence of cough and sore throat, as these are more critical side effects to control in these types of interventions.
In conclusion, spraying $4 \%$ lidocaine hydrochloride on the supra- and subglottic areas is effective in decreasing the occurrence of peri-extubation cough. The severity of sore throat remained low after procedures lasting less than two hours, and we presume that the use of liquid instead of air in the ETT cuff contributes to this low level of pain in all four groups. Finally, 2\% intracuff alkalinized lidocaine alone had no effect on decreasing the incidence of cough at extubation in short duration surgeries.

Acknowledgements The authors sincerely thank J.P. Tétrault MD, and we are grateful to Nathalie Carrier at the Centre de Recherche Clinique Etienne-Lebel for her support with statistical evaluations.

Funding This project was funded entirely by intramural departmental sources dedicated to research projects. This work is supported by a department stipend held by Y.S. and R.M.

Competing interests None declared.

\section{References}

1. Bennett $M H$, Isert PR, Cumming RG. Postoperative sore throat and hoarseness following tracheal intubation using air or saline to inflate the cuff - a randomized controlled trial. Anaesth Intensive Care 2000; 28: 408-13.

2. Biro P, Seifert B, Pasch T. Complaints of sore throat after tracheal intubation: a prospective evaluation. Eur $\mathrm{J}$ Anaesthesiol 2005; 22: 307-11.

3. McHardy FE, Chung F. Postoperative sore throat: cause, prevention and treatment. Anaesthesia 1999; 54: 444-53.

4. Jaensson M, Olowsson LL, Nilsson U. Endotracheal tube size and sore throat following surgery: a randomized-controlled study. Acta Anaesthesiol Scand 2010; 54: 147-53.

5. Wetzel LE, Ancona AL, Cooper AS, Kortman AJ, Loniewski GB, Lebeck $L L$. The effectiveness of $4 \%$ intracuff lidocaine in reducing coughing during emergence from general anesthesia in smokers undergoing procedures lasting less than 1.5 hours. AANA J 2008; 76: 105-8.

6. Minogue SC, Ralph J, Lampa MJ. Laryngotracheal topicalization with lidocaine before intubation decreases the incidence of coughing on emergence from general anesthesia. Anesth Analg 2004; 99: 1253-7.

7. Estebe JP, Dollo G, Le Corre P, et al. Alkalinization of intracuff lidocaine improves endotracheal tube-induced emergence phenomena. Anesth Analg 2002; 94: 227-30.

8. Estebe JP, Delahaye S, Le Corre P, et al. Alkalinization of intracuff lidocaine and use of gel lubrication protect against tracheal tube-induced emergence phenomena. Br J Anaesth 2004; 92: 361-6.

9. Estebe JP, Gentili M, Le Corre P, Dollo G, Chevanne F, Ecoffey C. Alkalinization of intracuff lidocaine: efficacy and safety. Anesth Analg 2005; 101: 1536-41.

10. Tazeh-Kand NF, Eslami B, Mohammadian $K$. Inhaled fluticasone propionate reduces postoperative sore throat, cough, and hoarseness. Anesth Analg 2010; 111: 895-8.

11. Huang YS, Hung NK, Lee MS, et al. The effectiveness of benzydamine hydrochloride spraying on the endotracheal tube cuff or oral mucosa for postoperative sore throat. Anesth Analg 2010; 111: 887-91. 
12. Hung NK, Wu CT, Chan SM, et al. Effect on postoperative sore throat of spraying the endotracheal tube cuff with benzydamine hydrochloride, 10\% lidocaine, and 2\% lidocaine. Anesth Analg 2010; 111: 882-6.

13. Ebneshahidi A, Mohseni M. Strepsils ${ }^{\circledR}$ tablets reduce sore throat and hoarseness after tracheal intubation. Anesth Analg 2010; 111: 892-4.

14. Canbay O, Celebi N, Sahin A, Celiker V, Ozgen S, Aypar U. Ketamine gargle for attenuating postoperative sore throat. $\mathrm{Br} \mathbf{J}$ Anaesth 2008; 100: 490-3.

15. Thomas $S$, Beevi $S$. Dexamethasone reduces the severity of postoperative sore throat. Can J Anesth 2007; 54: 897-901.

16. Gonzalez RM, Bjerke RJ, Drobycki $T$, et al. Prevention of endotracheal tube-induced coughing during emergence from general anesthesia. Anesth Analg 1994; 79: 792-5.

17. Diachun CA, Tunink BP, Brock-Utne JG. Suppression of cough during emergence from general anesthesia: laryngotracheal lidocaine through a modified endotracheal tube. J Clin Anesth 2001; 13: 447-51.

18. Soltani HA, Aghadavoudi $O$. The effect of different lidocaine application methods on postoperative cough and sore throat. J Clin Anesth 2002; 14: 15-8.
19. Navarro RM, Baughman VL. Lidocaine in the endotracheal tube cuff reduces postoperative sore throat. J Clin Anesth 1997; 9: 394-7.

20. Mazzone $S B$. An overview of the sensory receptors regulating cough. Cough 2005; 1: 2.

21. Adcock JJ, Douglas GJ, Garabette M, et al. RSD931, a novel anti-tussive agent acting on airway sensory nerves. Br J Pharmacol 2003; 138: 407-16.

22. Shroff PP, Patil V. Efficacy of cuff inflation media to prevent postintubation-related emergence phenomenon: air, saline and alkalinized lignocaine. Eur J Anaesthesiol 2009; 26: 458-62.

23. Seegobin RD, van Hasselt GL. Aspiration beyond endotracheal cuffs. Can Anaesth Soc J 1986; 33: 273-9.

24. Navarro LH, Braz JR, Nakamura G, Lima RM, Silva Fde P, Modolo NS. Effectiveness and safety of endotracheal tube cuffs filled with air versus filled with alkalinized lidocaine: a randomized clinical trial. Sao Paulo Med J 2007; 125: 322-8. 